\title{
Association Study of the Role of GLUT2 Receptor in Dental Caries Susceptibility, Dietary Habits and Body Mass Index (BMI)
}

\author{
Karayasheva D. ${ }^{1}$, Glushkova M. ${ }^{2}$, Kadiyska T. ${ }^{2,3}$, Boteva E. ${ }^{1}$ \\ ${ }^{1}$ Department of Conservative Dentistry, Faculty of Dental Medicine, Medical University, Sofia, Bulgaria \\ ${ }^{2}$ Genetic Medico-Diagnostic Laboratory Genica, Sofia, Bulgaria \\ ${ }^{3}$ Department of Medical Chemistry and Biochemistry, Medical Faculty, Medical University, Sofia, Bulgaria
}

\begin{abstract}
It is well known that various risk factors contribute to dental caries development and progression. Recent genome-wide association studies (GWAS) have led to the identification of gene locis associated with the risk of dental caries development and progression. GLUT2 is a member of the glucose transporter proteins, which has been associated with a higher habitual consumption of sugar and is a good potential candidate for caries development. For determination of GLUT2 gene polymorphism (rs5400, Thr110Ile) and its relation to dental caries susceptibility, an association clinical study of 108 Bulgarian volunteers, students in Sofia Medical University was performed. The participants completed a questionnaire about their dietary habits, snacks between meals, and BMI. Based on their DMFT (decayed, missing, filled teeth) scores, they were classified into three groups: caries free (CF, DMFT=0), low caries experience (LCE, DMFT $\leq 5)$ and high caries experience (HCE, DMFT $\geq \quad$ 9). DNA analysis was performed with a polymerase chain reaction (PCR) and direct sequencing. The data was processed by using IBM SPSS Statistics v19. Significant differences for the allele and genotype frequencies were not found between the three DMFT groups (CF, LCE and HCE). The Ile allele carriers had higher BMI $(23,4$ vs 22,3$)$ and were more frequently snacking between meals $(74 \%$ vs $63,5 \%)$. From the results can be concluded that the GLUT2 receptor gene is likely to be associated with dental caries development in older Bulgarian population. It can be related to the individuals' BMI and dietary habits.
\end{abstract}

Keywords: genetic factors, candidate genes, dental caries, GLUT-2, BMI

\section{Introduction}

Dental caries is the most common oral disease affecting humans. It is suggested that several risk factors contribute to dental caries development and progression. The classical current dogma is related to the cariogenic bacteria of the oral cavity: mutans streptococci and lactobacilli counts, higher sugar consumption and lower oral hygiene. All these are associated with dental caries susceptibility.

In the last decade various genetic, microbiological and environmental factors that may play a role in dental caries formation were studied. The importance of genetic factors in dental caries was recognized in early studies of the disease, and are illustrated best by studies of monozygotic and dizygotic twins. However, the role of particular predisposing genes has not been clearly defined.

Recent genome-wide association studies (GWAS) have led to the identification of few new loci associated with the risk of dental caries development. They were found to code genes related to the teeth development, host's immune response, metalloproteinases, as well as genes that determine the type of metabolism and eating behavior [Wang Q, 2013, Shaffer JR 2013, Wang X 2012]. The encode factors that support the energy homeostasis, sensory characteristics, food preferences and dietary habits [Eny, KM, El-Sohemy, A, 2010], representate examples of such genes like LEPR (Homo sapiens leptin receptor), NMB (Homo sapiens neuromedin B), TAS2R38 (Homo sapiens taste receptor, type 2, member 38), SLC2A2/GLUT2 (Solute carrier family 2 (facilitated glucose transporter) member 2).
A single study investigated the role of Thr110Ile genetic variant located in the GLUT2 gene and dental caries susceptibility. In 2013, Kulkarni et al. published an association study which examined the relationship between changes in the GLUT2 and TAS1R2 genes and the risk for dental caries. They found that the GLUT2 and TAS1R2 genotypes individually and in combination are associated with caries risk [Kulkarni et al., 2013]. The published results encouraged the analysis of the caries risk and its influence, from a possible functional consequences of changes in the GLUT2 gene in Bulgarian population.

The aim of the present study was to evaluate the role of GLUT2 gene polymorphism (rs5400) in dental caries susceptibility, dietary habits and BMI in a group of 108 Bulgarian medical students with mean age 22.3 years.

\section{Materials and Methods}

More then 140 subjects, all of them students in Sofia Medical University, completed a questionnaire about their ethnicity, parents education and social environment, oral hygiene habits and dietary habits (meal frequency, snacking between meals, food preferences and dietary composition), fluoride exposures, orthodontic treatment, frequency of preventive interventions, self-evaluation of salivary flow, medical history, BMI. One hundred and eight of them, 108 (44 males and 64 females) fulfilled the initial requirements for being ethnically Bulgarians, clinically healthy, without systemic diseases or generalized periodontal inflammations, perfect oral hygiene habits and at least one dental 


\section{International Journal of Science and Research (IJSR) \\ ISSN (Online): 2319-7064 \\ Index Copernicus Value (2013): 6.14 | Impact Factor (2014): 5.611}

examination per year. The age range was between 22-30 years, mean 23 for male and female volunteers. The clinical examinations were performed with dental mirrors, explorers, artificial light and photo-polymerizing lamps. Radiographs were not performed for diagnostic purposes.

The study was conducted according to the World Medical Association Declaration and additionally approved by the Ethics Committee of Sofia Medical University. Written informed consent form was obtained from all participants prior to genetic testing.

The studied subjects were classified according to the caries experience level using their DMFT scores. They were divided into three groups: caries free CF $(\mathrm{DMFT}=0, \mathrm{n}=23)$, low caries experience LCE (DMFT $\leq 5, n=43$ ) and high caries experience HCE (DMFT $\geq 5, \mathrm{n}=42$ ). Mean DMFT is 6.45 . Epithelial buccal cells were collected in $2 \mathrm{ml}$ sterile, plastic containers (Eppendorf type). Each container was labeled with the subject's name and an individual number. The samples were collected between 9 and 11.30 a.m. after normal hygiene procedures and breakfast habits.

The DNA was extracted from buccal cells by the Chelex ${ }^{\circledR}$ 100 (Bio-Rad Laboratories, Hercules, CA) extraction technique. The vials with buccal cells were centrifuged at 7,500 rpm for $15 \mathrm{~min}$, and the supernatant was removed. Then the pellet was resuspended by mixing it in $150 \mu \mathrm{l}$ of a 5\% Chelex 100 resin and Proteinase K solution, which was followed by incubation at $56^{\circ} \mathrm{C}$ for 2 hours in a dry heat block. The mixture was boiled for $10 \mathrm{~min}$ and then chilled on ice for $5 \mathrm{~min}$. It was then centrifuged at 12,000 rpm for $10 \mathrm{~min}$. The supernatant was carefully removed, with the Chelex being avoided. The DNA was stored at $-20^{\circ} \mathrm{C}$ prior to analysis.

The rs5400 variant is located in exon 3 of the GLUT2 gene resulting in amino acid substitution of Thr with Ile at position 110 of the protein. The genetic analysis included polymerase chain reaction (PCR) and direct sequencing. DNA fragments from exon 3 of the GLUT2 gene were amplified by the use of primer pairs GLUT2-F 5'CACGTAACAAACACTTTAAAGACAAA-3' and GLUT2-R 5'-GGTCATGAGTTGAAAAAACAACTCTA$3^{\prime}$. PCR amplification was performed in a $25 \mu \mathrm{l}$ volume containing $100 \mathrm{ng}$ of genomic DNA. The thermal cycles were initiated for 5 minutes at $95^{\circ} \mathrm{C}$, followed by 30 cycles of 40 seconds at $95^{\circ} \mathrm{C}, 30$ seconds at $60^{\circ} \mathrm{C}$, and 30 seconds at $72^{\circ} \mathrm{C}$, and a final extension at $72^{\circ} \mathrm{C}$ for 10 minutes.

Statistical analysis was performed using IBM SPSS Statistics v19. A one-sided comparison of allele and genotype frequencies in the different groups was applied with the Fisher's exact probabilities t-test. The values of the age, body mass index and DMFT values were tested for equality of variance between the groups and then compared using the independent samples T-test. The significance threshold was set between at 0.5 and 0.2 due to the number of the subjects, very high homogeneity of the group and the mean age 22.3 and narrow age range. All p-values are presented in tables displaying the $\pm \mathrm{SE}$ or $\mathrm{SD}$ of the means.

\section{Results}

All 108 volunteers were successfully genotyped for GLUT2 Thr110Ile polymorphism. Based on the genotype data, individuals were divided into carriers or non-carriers groups of the minor Ile allele. The distribution of genotypes according to DMFT scores and BMI is shown in Table 1. For GLUT2 (rs5400), the overall reported minor allele frequency (MAF) is 21,5\% in this study. In other European populations it is reported to be close to $12 \%$, but in different age and social groups. For the purposes of the working null hypothesis in the present study the participants were divided according to their DMFT scores. Differences for the allele and genotype frequencies were found between the CF, LCE and HCE groups (Tables 2 and 3, in comparison with the subjects' BMIs. The Ile allele carriers had significantly higher BMIs $(23,4$ vs 22,3) and had more snacks between meals $74 \%$ vs $63,5 \%(p=0.25)$. Ile allele carriers preferred more frequently food with a high glycemic index.

From tabl. 1 and 2 is obvious that all decayed and restored teeth are having an important impact on the allelic distribution because the highest difference between the statistic groups $(p=0.45)$ was observed when caries free subjects are compared with the other two groups. This allelic differences could show genotype significant differences $(p=0.58)$ if the subjects were older and the groups were larger. Statistically significant differences were found in these 108 subjects into the genotypes between low and high caries activity groups, CF, LCE and HCE, related to the differences in the regularity of meals, frequency of snacks and high glycemic food index.

\section{Discussion}

The correct choice of food products is important not only to maintain a healthy lifestyle and good oral health. Various genetic markers are associated with food behavior, including the LEPR gene (Homo sapiens leptin receptor), which is an important hormone for the regulation of food intake. [Bouchard L et al., 2004]. Recently, the role of several taste receptors has been evaluated in relation to food selection [Garcia-Bailo B et al., 2009; Fushan AA et al., 2009].

There are few theories of the etiology of dental caries, focused on the importance of dietary habits. Changing patterns of consumption of sugar intake are also important. The cariogenicity of one food depends on various factors including the composition of the whole diet, the frequency of food consumption, the stickness of the food and how long the food remains in the mouth. It has been shown that a higher carbohydrate and lipid but less in proteins diet affects the process of biomineralization and enamel resistance. This type of diet could cause multiple-deep carious lesions (1). High protein diets are favorable for enamel biomineralization and resistance. It is well known that the increased amount of carbohydrates, particularly sucrose and its higher frequency intake is associated with the development not only of carious lesions [Eny et al., 2008, Kulkarni et al., 2013] but with the development of genetically transmitted diseases like diabetes, obesity, hyperlipidemia, osteoporosis, etc (2). 


\section{International Journal of Science and Research (IJSR) \\ ISSN (Online): 2319-7064 \\ Index Copernicus Value (2013): 6.14 | Impact Factor (2014): 5.611}

The breakdown of carbohydrates begins in the oral cavity and the sugars contained in to the ingested food are broken down from a large number of salivary enzymes. The entry of the glucose molecule into the bloodstream, depends on the tissue type, through facilitated or passive diffusion. In the beta-cells of the pancreas, glucose enters the cell through the high-capacity facilitative glucose transporter, named GLUT2 and thus regulating insulin secretion [Marty et al., 2007]. GLUT2 participates in the bidirectional transmembrane transport of glucose and is an important factor in maintaining the blood sugar levels [Brown, 2000]. GLUT2 is also expressed in the liver, the kidney and the intestines. Recent studies have demonstrated the presence of glucose transporters (GLUT2, GLUT5 and SGLT1) in the taste receptor cells (TRCs) of the tongue.

Eny et al. are using two methods of dietary assessment and discovered that GLUT2 gene polymorphism rs5400 is associated with a higher sugar intake in two different populations [Eny et al., 2008]. The expression of GLUT2 in the regions of the brain is associated with the regulation of food intake and is included in the unit of the central glucose sensor system.

Kulkarni et al. also explored the polymorphism rs5400 (p.Ile110Thr) of the GLUT2 gene and found that carriers of allele Ile are with increased daily intake of carbohydrates compared with genotype Thr/Thr. Subsequent analyses have shown that carriers of the Ile allele consumed significantly more sucrose, fructose and glucose. Their results demonstrated that carriers of polymorphism rs5400 were at greater risk for development of dental caries [Kulkarni et al., 2013].

The discovered association of the rs5400 polymorphism of GLUT2 gene with caries susceptibility, BMI and dietary habits may contribute to the caries risk in our populations. The study designs and the relatively small sample in our study (108 participants) may also explain the findings. The positive association from the study of Kulkarni et al. was carried out in even smaller groups of 80 individuals. These two studies investigate two different populations (Canadians and Bulgarians) with different genetic backgrounds. In Kulkarni's study, 30\% of the participants were carriers of the minor Ile allele, while in this study the frequency was $21 \%$.

Despite the number of participants in this pioneer study for Bulgaria, the selected group of volunteers was characterized by a very high homogencity regarding the ethnicity, age (2032 year-olds), social status and education, parents education, nutritional and hygiene habits, health culture, motivation for their general and dental health care.

\section{Conclusions}

1) Statistically significant differences for this allele and genotype frequencies were not found between the three DMFT groups (CF, LCE and HCE) of young Bulgarian students. The Ile allele carriers had higher BMI (23,4 vs $22,3)$ and were more frequently snacking between meals (74\% vs 63,5\%).
2) From this study can be concluded that the GLUT2 receptor gene is likely to be associated with dental caries development may be in older Bulgarian population, related to the individuals' BMI and dietary habits. The role of GLUT2 gene variant as a risk factor for dental caries can be proved with a larger study of different age groups.

\section{Acknowledgements}

This research was financed from the Medical Scientific Council, Medical University of Sofia, Bulgaria (GRANT project №22/2014, contract №26/2014). The research team is grateful to the students, who volunteered for this survey.

\section{References}

[1] Boteva E. The influence of different dietary regimes on etiolopathogenesis of dental caries. Medical University, Diss.,Sofia, 1988

[2] Hadjieva H., E. Boteva. Osteoporossis and nutrition in elderly dental patients. Stomatologia, Sofia, 1989, 3, p.69

[3] Bouchard L, Drapeau V, Provencher V, Lemieux S, Chagnon Y, Rice T, Rao DC, Vohl MC, Tremblay A, Bouchard C, Pérusse L. Neuromedin beta: a strong candidate gene linking eating behaviors and susceptibility to obesity. Am J Clin Nutr. 2004 Dec;80(6):1478-86

[4] Brown GK. Glucose transporters: structure, function and consequences of deficiency. J Inherit Metab Dis. 2000 May;23(3):237-46.

[5] Eny KM, Wolever TM, Corey PN, El-Sohemy A. Genetic variation in TAS1R2 (Ile191Val) is associated with consumption of sugars in overweight and obese individuals in 2 distinct populations. Am J Clin Nutr. 2010 Dec;92(6):1501-10. doi: 10.3945/ajcn.2010.29836. Epub 2010 Oct 13.

[6] Eny KM, Wolever TM, Fontaine-Bisson B, El-Sohemy A. Genetic variant in the glucose transporter type 2 is associated with higher intakes of sugars in two distinct populations. Physiol Genomics. 2008 May 13;33(3):355-60. doi: 10.1152/physiolgenomics.00148.2007. Epub 2008 Mar 18.

[7] Fushan AA, Simons CT, Slack JP, Manichaikul A, Drayna D. Allelic polymorphism within the TAS1R3 promoter is associated with human taste sensitivity to sucrose. Curr Biol. 2009 Aug 11;19(15):1288-93

[8] Garcia-Bailo B, Toguri C, Eny KM, El-Sohemy A. Genetic variation in taste and its influence on food selection. OMICS. 2009 Feb;13(1):69-80.

[9] Kayano T1, Burant CF, Fukumoto H, Gould GW, Fan YS, Eddy RL, Byers MG, Shows TB, Seino S, Bell GI.J. Human facilitative glucose transporters. Isolation, functional characterization, and gene localization of cDNAs encoding an isoform (GLUT5) expressed in small intestine, kidney, muscle, and adipose tissue and an unusual glucose transporter pseudogene-like sequence (GLUT6). Biol Chem. 1990 Aug 5;265(22):13276-82.

[10] Kulkarni GV, Chng T, Eny KM, Nielsen D, Wessman C, El-Sohemy A. Association of GLUT2 and TAS1R2

\section{Volume 5 Issue 3, March 2016}




\section{International Journal of Science and Research (IJSR) \\ ISSN (Online): 2319-7064 \\ Index Copernicus Value (2013): 6.14 | Impact Factor (2014): 5.611}

genotypes with risk for dental caries. Caries Res. 2013;47(3):219-25. doi: 10.1159/000345652. Epub 2012 Dec 19.

[11] Marty N, Dallaporta M, Thorens B. Brain glucose sensing, counterregulation, and energy homeostasis. Physiology (Bethesda). 2007 Aug;22:241-51.

[12] Shaffer JR et all. Genome wide association scan for childhood caries implicates novel genes J Dent Res 2012, 90, 1457-1462

[13] Shaffer JR, Feingold E, Wang X, Lee M, Tcuenco K, Weeks DE, Weyant RJ, Crout R, McNeil DW, Marazita
ML. GWAS of dental caries patterns in the permanent dentition. J Dent Res. 2013 Jan;92(1):38-44

[14] Wang Q, Jia P, Cuenco KT, Feingold E, Marazita ML, Wang L, Zhao Z. Multi-dimensional prioritization of dental caries candidate genes and its enriched dense network modules. PLoS One. 2013; 8(10): e76666.

[15] Wang XJ et all. Genes and their effects on dental caries (tooth decay) may differ between primary and permanent dentitions Car Res 2010, 44,277-284

[16] Merigo F, Benati D, Cristofoletti M, Osculati F, Sbarbati A. Glucose transporters are expressed in taste receptor cells. J Anat. 2011 Aug;219(2):243-52.

Table 1: Comparison of subject characteristics by GLUT2 genotype

\begin{tabular}{|c|c|c|c|}
\cline { 2 - 4 } \multicolumn{1}{c|}{} & \multicolumn{3}{c|}{ GLUT2 genotype } \\
\cline { 2 - 4 } \multicolumn{1}{c|}{} & $\begin{array}{c}\text { Thr/Thr } \\
(\mathbf{n}=\mathbf{8 5})\end{array}$ & $\begin{array}{c}\text { Ile carriers } \\
(\mathbf{n}=\mathbf{2 3})\end{array}$ & p value \\
\hline Age, years & $22.98+/-.24$ & $23.65+/-.58$ & 0.23 \\
\hline Gender & 35 & 9 & 0.86 \\
\hline Male & 50 & 14 & 0.71 \\
\hline Female & $7.05+/-.78$ & $6.43+/-1.28$ & 0.21 \\
\hline DMFT & $22.35+/-.37$ & $23.41+/-.91$ & \\
\hline BMI $\left(\mathrm{kg} / \mathrm{m}^{2}\right)$ & \multicolumn{3}{|c}{} \\
\hline \multicolumn{3}{|c|}{ Mean \pm SEM (For all values) }
\end{tabular}

Table 2: Allelicfrequencies of the GLUT2 polymorphism among the subjects, subsequently divided according to DMFT scores

\begin{tabular}{|c|c|c|c|}
\hline \multirow[b]{2}{*}{ group } & Thr allele & Ile allele & \multirow[b]{2}{*}{$\mathrm{p}$ value } \\
\hline & $\begin{array}{c}n(\%) \\
n=191(88)\end{array}$ & $\begin{array}{c}\mathrm{n}(\%) \\
\mathrm{n}=25(12)\end{array}$ & \\
\hline CF & $40(87)$ & $6(13)$ & \multirow[b]{2}{*}{0.45} \\
\hline HCE+LCE & $151(78)$ & $19(22)$ & \\
\hline CF & $40(87)$ & $6(13)$ & \multirow[b]{2}{*}{0.53} \\
\hline HCE & $74(90)$ & $10(10)$ & \\
\hline LCE & $77(87)$ & $9(13)$ & \multirow[b]{2}{*}{0.48} \\
\hline HCE & $74(90)$ & $10(10)$ & \\
\hline $\mathrm{CF}+\mathrm{LCE}$ & 117(87) & 15(13) & \multirow[b]{2}{*}{0.53} \\
\hline HCE & $74(90)$ & $10(10)$ & \\
\hline
\end{tabular}

Table 3: Genotype frequencies of the GLUT2 polymorphism among the subjects, subsequently divided according to DMFT scores and dietary habits

\begin{tabular}{|c|c|c|c|}
\hline \multirow[b]{2}{*}{ group } & Thr/Thr & */Ile & \multirow[b]{2}{*}{$\mathrm{p}$ value } \\
\hline & $\begin{array}{c}\mathrm{n}(\%) \\
\mathrm{n}=85(79)\end{array}$ & $\begin{array}{c}n(\%) \\
n=23(21)\end{array}$ & \\
\hline $\mathrm{CF}$ & $18(78)$ & $5(22)$ & \multirow[b]{2}{*}{0.58} \\
\hline $\mathrm{HCE}+\mathrm{LCE}$ & $67(79)$ & $18(21)$ & \\
\hline CF & $18(78)$ & $5(22)$ & \multirow[b]{2}{*}{0.55} \\
\hline HCE & $32(76)$ & $10(24)$ & \\
\hline LCE & $35(81)$ & $8(19)$ & \multirow[b]{2}{*}{0.37} \\
\hline HCE & $32(76)$ & $10(24)$ & \\
\hline $\mathrm{CF}+\mathrm{LCE}$ & $53(80)$ & $13(20)$ & \multirow[b]{2}{*}{0.39} \\
\hline HCE & $32(76)$ & $10(24)$ & \\
\hline Regular meal frequencies & 11(13) & $4(17)$ & 0.40 \\
\hline Snacking between meals & $54(63,5)$ & $17(74)$ & 0.25 \\
\hline High glycemic index food & $60(70,5)$ & $15(75)$ & \multirow[t]{2}{*}{0.40} \\
\hline preferences & & & \\
\hline
\end{tabular}

